Trevor I. Anatol FRCs, ${ }^{\star}$ Phyllis Pitt-Miller FRCA, ${ }^{\dagger}$ Yvette Holder M PHIL ${ }^{\ddagger}$

\section{Trial of three methods of intraoperative bupivacaine analgesia for pain after paediatric groin surgery}

Purpose: To evaluate the relative effectiveness of three techniques of regional anaesthesia in the provision of postoperative analgesia in children.

Methods: Randorn assignment was made of 183 children scheduled for groin surgery to one of three groups. Bupivacaine $0.5 \%$ plain $\left(2 \mathrm{mg} \cdot \mathrm{kg}^{-1}\right)$ was injected by the surgeon after skin incision. Group A received wound infiltration. Group B had regional nerve blockade. Group C had a combination of both methods. Postoperatively, pain was assessed using the CHEOPS behavioural scale at half hourly intenvals until discharge home. Satisfactory pain control was arbitrarily defined as a CHEOPS score of ssix. Potential differences among the groups were sought using graphical representation of mean pain scores, the frequencies of maximum pain scores, and the incidence of postoperative vomiting and oral analgesic consumption.

Results: Fifteen patients had to be excluded from analysis. This left 61 patients in Group A, 55 in Group B, and 52 in Group $C$. There were no demographic differences among the groups. No differences were demonstrated among the groups either in CHEOPS pain scores at any observation point $(P=>0.8)$, or in the incidence of vomiting or need for postoperative analgesia. $(P=0.52$ and $P=0.41$ respectively). Overall, $80 \%$ of the observations made $(1 / 35 / 1425)$ met our definition of satisfactory pain control. A post hoc calculation of the power of the study confirmed sufficient power to detect a $5 \%$ difference among groups.

Conclusion: All three methods achieved analgesia with $80 \%$ of the pain scores meeting our definition of satisfactory pain control. None of the techniques enjoyed any apparent advantage.

Objectif : Évaluer l'efficacité relative de trois techniques d'anesthésie régionales administrées en vue de procurer l'analgésie postopératoire à des enfants.

Méthodes : Cent quatre-vingt-trois enfants programmés pour une chirungie inguinale ont été assignés à un de trois groupes. Tous les enfants ont reçu de la bupivacaine $0,5 \%$ simple $\left(2 \mathrm{mg} \cdot \mathrm{kg}^{-1}\right)$ injectée par le chinurgien après lincision de la peau. Dans le groupe $A$, on infiltrait la plaie, dans le groupe $B$, on administrait un bloc nerveux, et dans le groupe

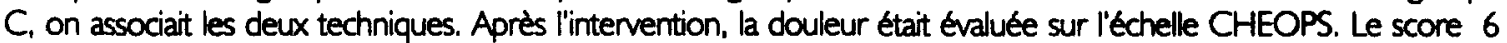
était considéré comme révélateur d'un soulagement satisfaisant. Les différences intergroupes potentielles ont été recherchées à l'aide d'une projection graphique du score de douleur moyen, de la fréquence des scores de douleur maximale et de lincidence des vomissements postopératoires et de la prise orale d'analgésique.

Résultats : Quinze patients ont été exclus de l'analyse. Ce qui laissait 61 patients au groupe A, 55 au groupe B et 52 au groupe $C$. Les groupes ne différaient pas sous l'aspect démographique. On n'a pas démontré de différences entre les groupes que ce soit sur l'échelle CHEOPS à tous les moments d'observation $(P=0,8)$ ou sur l'incidence des vomissements et les besoins d'analgésie postopératoire (respectivement $P=0,52$ et 0,41 ). Au total, $80 \%$ des observations ( 1 135/I 425) rencontraient nos critères de soulagement de la douleur. Un calcul ultérieur confirmait que la puissance de l'étude était suffisante pour détecter une différence intergroupe de $5 \%$.

Conclusion : Les trois méthodes procuraient l'analgésie avec $80 \%$ des scores conformes à nos critères de soulagement. Aucune des techniques n'offrait d'avantages particuliers sur les autres.

From the Units of Paediatric Surgery ${ }^{\star}$ \& Anaesthesia and Intensive Care, ${ }^{\dagger}$ Department of Clinical Surgical Sciences, Faculty of Medical Sciences, University of the West Indies, St. Augustine, Trinidad, West Indies and the Department of Epidemiology, Caribbean Epidemiology Centre, $\$$ Port of Spain, Trinidad.

Address correspondence to: Dr. Phyllis Pitt-Miller FRCA; Phone: 809-645-2640; Fax: 809-663-4319.

Accepted for publication June 25, 1997. 
T

HE nausea, vomiting and sedation which are frequently associated with the administration of parenteral opioids detract from their usefulness as pre and post-operative agents in paediatric day care surgery. ${ }^{1}$ One way to circumvent their use in children is to substitute local anaesthetic blockade. ${ }^{2}$ A solution of bupivacaine $0.5 \%$, which has a prolonged duration of action of four to eight hours, ${ }^{3}$ is particularly suitable for use in a day care setting. It is still unclear, however, whether the local anaesthetic is best employed in regional nerve blockade, wound infiltration, or both.

A prospective trial was designed to compare the efficacy of the intraoperative use of bupivacaine as a nerve block, wound infiltrate and a combination of the two in day care groin surgery.

\section{Methods}

After approval from our hospital ethics committee, a consecutive series of children, who required a unilateral groin crease incision for surgery scheduled at the same day unit of the Eric Williams Medical Sciences Complex, was entered into the trial, over the period November 1991 to May 1994.

Informed consent was obtained in writing from the parent or guardian of each child. The children were allocated to one of three groups - A, B or C - by the use of a table of random numbers. Small blocks of three were used to ensure an even spread of numbers between the groups.

Premedication was standardized with a dose of trimeprazine tartrate $2 \mathrm{mg} \cdot \mathrm{kg}^{-1}$ po two hours pre-operatively. Prior to induction, ECG, non invasive blood pressure (NIBP) and pulse oximetry probes were applied and baseline values obtained. Anaesthesia was induced in each case with halothane $2 \%$ in a $50 \%$ mixture of nitrous oxide and oxygen. Intravenous induction was avoided. The concentration of halothane was adjusted as indicated to maintain satisfactory anaesthesia. No intraoperative opioids were used.

Each child had a standard groin crease incision. Bupivacaine $0.5 \%$ was instilled by the surgeon upon exposure of the external oblique aponeurosis. A dose of $2 \mathrm{mg} \cdot \mathrm{kg}^{-1}\left(0.4 \mathrm{ml} \cdot \mathrm{kg}^{-1}\right)$ was drawn up for each patient. Exceeding this maximum is thought to be inadvisable particularly in infants. ${ }^{1,4}$ Patients assigned to group $\mathrm{A}$ had wound infiltration alone. Those in group B had blockade of the ilio-inguinal and iliohypogastric nerves performed through the exposed external oblique aponeurosis. In practice, the confines of this space precluded the introduction of more than five millilitres of the solution, which was injected in the recommended fan-shaped distribution one to two fingers' breaths, according to age, medial and caudal to the anterior superior iliac spine, ${ }^{4,5}$ Children in group $\mathrm{C}$ had a combination of the two methods, one quarter of the total volume being used for the nerve block and the balance for wound infiltration.

Five minute observations were recorded during surgery and the patient was transferred to the postoperative recovery room on achieving full control of reflexes. Patients were monitored in the post anaesthetic care unit with ECG, pulse oximetry, NIBP and clinical observations and discharged to the Preparation area when an Aldrate score of eight was achieved.

Pain was assessed by a clinical research assistant, an experienced nurse, - half hourly after leaving the operating theatre until the child was discharged home later in the day. This observer was unaware of the method of analgesia used. Postoperative pain medication was limited to paracetamol $10 \mathrm{mg} \cdot \mathrm{kg}^{-1}$ every four hours as required, administered by a clinic nurse, who was unaware of the group assignment, based on her impression of need.

The clinical research assistant used the Children's Hospital of Eastern Ontario behavioural Pain Scale (CHEOPS) to assign a quantitative pain measure at each observation point. This scale assigns a numerical value to six behaviour patterns viz. cry, facial expression, verbalization, body posture, leg movements and attempts to touch the wound (see Appendix ${ }^{6}$ ).

A score of six on the CHEOPS scale depicts a child, who is not crying, has a facial expression at least neutral, is not indicating pain verbally, has an inactive torso, is not touching or grabbing at the wound and is lying with legs relaxed. This combination suggests a lack of severe pain and, accordingly, a score of $\leq$ six was taken to be a reflection of satisfactory pain control. For similar reasons, by a score of $\geq$ nine was taken as an indication of severe pain and treatment failure.

The pain scores obtained, as well as demographic details, procedure performed, the incidence of vomiting and postoperative analgesic consumption, were entered and stored in a database, via Epi Info, ${ }^{7}$ until the end of recruitment to the trial.

Using the BMDP statistical software package ${ }^{8}$ exploration was undertaken of the effect of all measured exposure variables,viz the experimental variables (group assignment) potential confounders (demographic data, surgical procedure performed) and a covariate (the time intervals over which pain was measured) - on the final outcome variable i.e., the CHEOPS pain score. In addition to the actual observed pain scores, other summary indicators of outcome were examined. These were individual mean pain scores, individual maximum pain scores, the incidence of postoperative vomiting, the time 
lapse to first postoperative analgesic administration, and analgesic consumption prior to discharge home.

Associations were tested between exposure and outcome variables in each group. The repeated pain scores and the maximum scores were dichotomised with scores of nine or more indicating the undesirable outcome of severe pain. A stepwise logistic regression was then performed to obtain the model most reflective of the relationship between the exposure variables and the outcomes. To cater for the lack of independence between repeated measurements on the same subjects, suspected inherent non-normality of the data and imbalance due to unequal numbers of observations, for analysis of unbalanced repeated measured models was applied to the repeated observations. For all statistical estimates calculated, $P<0.05$ was considered significant.

A post-hoc determination of the power of the study to test the hypotheses generated was also done.

\section{Results}

Observations were obtained on 183 children. Twelve of these records had to be excluded because of an inadequate period of postoperative observation (less than three hours), the inadvertent use of intraoperative opioids, or missing data forms. Another three children were repeat entries into the study, operated on for contralateral hernias on separate occasions but randomised to the same study group. The second entries were discarded as a possible source of bias. The remaining 168 records available for analysis comprised 61 in group A, 55 in group $B$ and 52 in group $C$. There was no differences among the groups in respect of age and sex $(P=0.95$ and $P=0.17$ respectively). One hundred and eighteen procedures were undertaken for the cure of an inguinal hernia, 11 for hydrocoele and 39 for undescended testes. These were evenly spread between the two groups (Table I). One child in each group developed a skin rash postoperatively but no episodes of delayed ambulation or urinary retention were documented.

TABLE I Distribution of demographic features and surgical procedures between groups

\begin{tabular}{lcccc}
\hline & \multicolumn{4}{c}{ Groups } \\
\hline Age: & A & B & C & n \\
5 yr & 37 & 33 & 30 & 100 \\
$6-12$ yr & 24 & 22 & 22 & 68 \\
Sex: & & & & \\
Male & 47 & 48 & 38 & 133 \\
Female & 14 & 7 & 14 & 35 \\
Procedure: & & & & \\
Herniotomy & 43 & 36 & 39 & 118 \\
Orchidopexy & 9 & 15 & 15 & 39 \\
Hydrococlc & & & & \\
Surgery & 6 & 3 & 2 & 11 \\
\hline
\end{tabular}

The pain scores for each method of administration were plotted against time. For group A, 78.1\% $(382 / 489)$ of observation periods reflected satisfactory pain control, with a score of six or less. The corresponding values for groups $\mathrm{B}$ and $\mathrm{C}$ were $79.9 \%(370 / 463)$ and $81 \%(383 / 473)$ respectively $\left(\mathrm{x}^{2}=0.25,2 \mathrm{df}\right.$, $P=>0.8)$. At the other end of the scale only $9.4 \%$ $(46 / 489)$ of observation periods in group A patients reflected the most undesirable outcome of a score of nine or more. This compares with $8.4 \%(39 / 463)$ in group B, and $5.9 \%(28 / 473)$ in group $C$ patients $\left(\mathrm{x}^{2}=3.9,2 \mathrm{df}\right.$, $P=>0.1)$. None of these differences approached statistical significance.

Graphical representation of the means of the three groups, to within one standard error of the mean, showed sufficient overlap to confirm the absence of difference among groups (Figure 1) Pairwise comparisons among the group means, using Welch's $t$ test, which does not assume equality of variances, showed no significant difference between groups $\mathrm{C}$ and $\mathrm{A}[\mathrm{P}(\mathrm{t}=1.34$, $1 \mathrm{df})=0.18)]$ or between $\mathrm{C}$ and $\mathrm{B}[\mathrm{P}(\mathrm{t}=1.19,1 \mathrm{df})=0.23]$. In like manner, the curves representing the distribution of mean pain scores at each postoperative observation point show no intergroup difference (Figure 2).

Several children received postoperative oral analgesia. These comprised $54.1 \%$ (33/61) of group A, $65.4 \%$ $(36 / 55)$ of group B and $55.8 \%(29 / 52)$ of group C patients $\left(\chi^{2}=1.73,2 \mathrm{df}, P=0.41\right)$. Also recorded was the fact that a score of 29 at a minimum of one observation point occurred in $49.2 \%(30 / 61)$ of group A, $50.9 \%$ $(28 / 55)$ of group B and $38.5 \%(20 / 52$ of group C patients).

Indirect measures of pain were also considered. There were no differences in the incidence of vomiting $\left(\chi^{2}=1.3,2 \mathrm{df}, P=0.52\right)$, or of analgesic consumption

Distribution of Group Mean Pain Scores (with 95\% Confidence Interval Limits

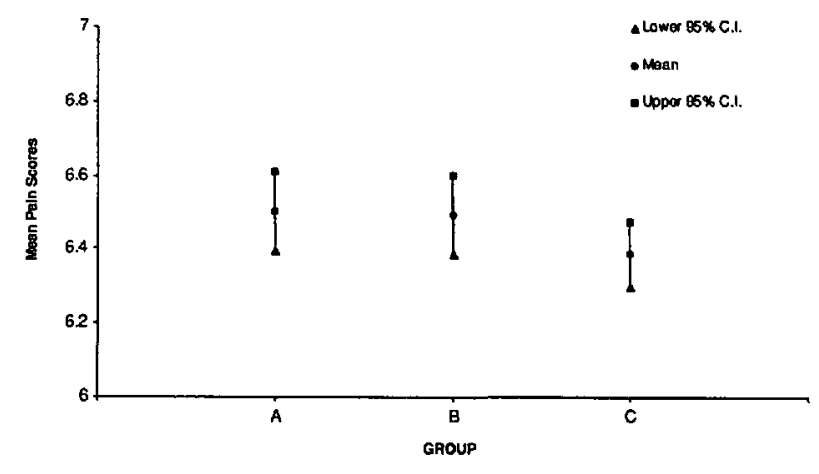

FIGURE I A composite graph of individual pain scores plotted against time shows a multimodal pattern 
Distribution of Mean Pain Scores at each Post-Operative Observation Poin

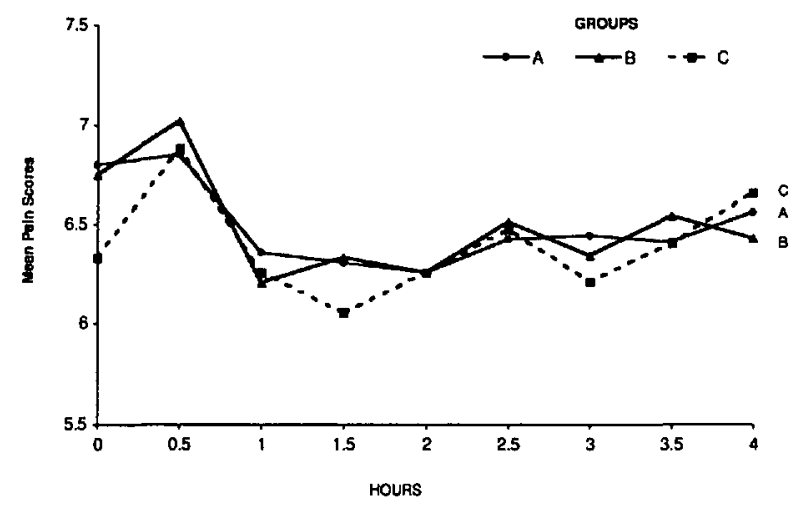

FIGURE 2 A comparison chart of the means of the three groups

$\left(\chi^{2}=1.7,2 \mathrm{df}, P=0.41\right)$ (Table II), or in the time lapse to the administration of the first postoperative oral analgesic $\left(\chi^{2}=5.3,6 \mathrm{df}, P=0.5\right)$, between the three groups.

Power analysis showed that the sample size of 168 patients exceeded the number required to attain a power of $80 \%$ to detect a difference of $5 \%$ in a population among whom at least $15 \%$ attain the tested attribute $^{9}$ (significant pain).

\section{Discussion}

The results are presented of a prospective randomised trial designed to assess the relative efficacy of the intraoperative use of bupivacaine $0.5 \%$ as a nerve block, wound infiltrate and a combination of the two in day care groin surgery. The local anaesthetic was injected, by the surgeon of the two in day care groin surgery, after exposure of the external oblique aponeurosis to ensure accuracy of the nerve block.

Previous studies have established that regional analgesia is well suited to use in same day operative procedures. Caudal anaesthesia and local anaesthesia are thought to have similar effects on postoperative care after herniotomy in children. ${ }^{10}$ For example, supplementary opioid requirements were similar after percutaneous nerve block and with caudal analgesia in 44 children undergoing herniotomy or orchidopexy. ${ }^{11}$ No difference in recovery times, pain scores, or requirement for additional analgesia were demonstrated in 41 children undergoing herniotomy or orchidopexy and who had received either caudal analgesia or percutaneous nerve block combined with skin infiltration, but the caudal technique mandated a longer stay in hospital. ${ }^{5}$ On the other hand, an apparent beneficial effect of caudal anaesthesia on emergence times, delayed onset of pain related behaviours and reduced opioid need facilitating earlier discharge when
TABLE II Incidence of vomiting and analgesic administration among groups

\begin{tabular}{lcccc}
\hline \multicolumn{5}{c}{ Groups } \\
\hline & $\mathrm{A}$ & $\mathrm{B}$ & $\mathrm{C}$ & $\mathrm{n}$ \\
No. of children vomited & 12 & 13 & 15 & 40 \\
No. receiving analgesics & 33 & 36 & 29 & 98 \\
Time to first dose analgesic: & & & & \\
$<1 \mathrm{hr}$ & 11 & 11 & 8 & 30 \\
$1-2 \mathrm{hr}$ & 13 & 11 & 6 & 30 \\
$>2 \mathrm{hr}$ & 9 & 14 & 15 & 38 \\
\hline
\end{tabular}

compared with wound infiltration, was demonstrated in a series of 70 children undergoing bilateral inguinal herniorrhaphy. ${ }^{12}$

More recently, in a larger series of 202 children undergoing unilateral herniotomy, an increased need for oral analgesia in the group treated by subcutaneous infiltration and percutaneous nerve blockade was counterbalanced by an increased incidence of delayed ambulation and prolonged hospital stay in the caudal group. ${ }^{10}$ Thus, any advantage for caudal anaesthesia may be limited to bilateral procedures and to situations where simple wound infiltration is not supplemented by regional nerve blockade.

Before these studies, percutaneous regional nerve block used alone had been shown to reduce general anaesthesia requirements as well as the need for postoperative codeine in a series of 156 children undergoing hernia repair ${ }^{4}$ and analgesic usage and activity level in 99 children undergoing the same procedure. ${ }^{13}$ Its combination with wound infiltration was later shown to reduce early postoperative opioid requirements in 40 adult men following herniorrhaphy ${ }^{14}$ and led to lower pain scales and reduced oral analgesic requirements in a controlled series of 30 adult males undergoing unilateral herniorrhaphy under lidocaine infiltration. ${ }^{15}$

One of the implications of these studies is that the combination of nerve block and wound infiltration is superior to that of wound infiltration alone. This trial was undertaken to compare directly the effect of the combination of both methods with either method alone.

Failure of nerve blockade is sometimes ascribed to difficulty in identifying the external oblique aponeurosis percutaneously in order to allow accurate subfacial infiltration of the regional nerves. The importance of using a small bore short bevel needle has been emphasized as a way to circumvent these problems. ${ }^{5,15}$ However, preliminary exposure of the external oblique, as was done in this series, allows accurate subfacial placement of the local anaesthetic under vision, and ensures anaesthesia of the major layer nerves in the area. ${ }^{16}$ 
The use of the CHEOPS behavioral scale sought to circumvent the potential difficulties with communicating pain inherent in any paediatric self reporting scale. ${ }^{1}$ Other indirect measures of pain used were the analgesic consumption and the incidence of vomiting. None of the measures used demonstrated any difference among the groups.

This study has several shortcomings. These include the lack of an a priori power analysis to predict the necessary sample size. Nevertheless, the post hoc analysis confirmed sufficient power to detect a $5 \%$ difference among the groups. The decision to exclude a control group rested on the fact that we thought that several previous control studies had established the benefits of intra-operative regional analgesia. In addition, the CHEOPS pain score was developed for use in the age groups one to seven years and it may not encompass changes in pain behaviour which occur in older children. ${ }^{1,10}$ Further, we were unable to factor in the effect of oral analgesics given postoperatively on subsequent pain scores.

The fact that reasonable pain control was only recorded in about $80 \%$ of observations is also cause for concern. In addition, $38 \%-51 \%$ of the children studied attained at least one score of $\geq 9$ or more, the chosen index of severe pain. This parallels the $54.1 \%$ to $65.4 \%$ judged to require postoperative oral analgesia at least once. It is possible that the use of mean pain scores obscured treatment failure in individual cases or, alternatively, the behavioural disturbances studied were an index of other than pain perception e.g., emergence from anaesthesia, parental separtion, hunger. The assessment of the need for analgesia by attendant nursing staff is known to vary widely and to be unreliable. This is despite the fact that attempts were made to ensure the accuracy of the nerve block by subfacial injection under direct vision. Complete local anaesthesia in hernia repair is thought to require infiltration at the level of the pubic tubercle, into the neck of the hernial sac as well as into the areas used in this series. ${ }^{18}$ In addition, despite the evidence of a lack of an effect of the particular procedure done on pain scores, the small numbers of procedures done apart from herniotomies may have obscured any possible influence. Particularly in procedures involving manipulation of the testis, the plane of surgical dissection may extend above the $T_{12} / L_{1}$, area supplied by the ilio-inguinal and iliohypogastric nerves. ${ }^{17}$

Apart from such technical considerations, it has been proposed that the addition of a local anaesthetic with a shorter onset of action infiltrated through the skin prior to incision would add the benefit of pre-emptive analgesia. ${ }^{18}$ In addition, the use of a systemic non-steroid anti-inflammatory drug (NSAID) both before and after surgery, might help to provide balanced analgesia and a closer approach to pain-free surgery. Use of these drugs has been shown to reduce opioid requirements. ${ }^{19}$ Administration of paracetamol and NSAIDs at regular intervals has been recommended for day care surgery in combination with a regional block, ${ }^{2}$ and the addition of an NSAID, albeit by the rectal route, to caudal block has been shown to reduce supplemental analgesic need when compared with the block alone in 39 children following circumcision, herniotomy and orchidopexy. ${ }^{20}$ However, NSAID's still require circumspection when used in paediatric patients and should be avoided in infants less than 3 months of age and used with caution in children with asthma. ${ }^{2}$

We failed to establish any difference in postoperative pain control whether intraoperative bupivacaine is used in wound infiltration, nerve block or a combination of the two, in a series of 168 children undergoing same day groin surgery. Since simple wound infiltration is simplest to apply, our study reinforces the view that simple wound infiltration with local anaesthesia should be encouraged in paediatric anaesthesia, ${ }^{21}$ particularly in a setting such as ours, which has limitations on highly trained personnel and monitoring facilities.

APPENDIX Behavioural definitions and scoring of $\mathrm{CHEOPS}^{6}$

\begin{tabular}{llll}
\hline Item & Behaviour & Score & Definition \\
\hline Cry & No cry & 1 & Child is not crying \\
& Moaning & 2 & Child is moaning or quietly vocalizing; silent cry \\
& Crying & 2 & Child is crying, but the cry is gentle or whimpering \\
& Scream & 3 & Child is in a full-lunged cry; sobbing: \\
& may be scored with complaint or without complaint \\
Facial & Composed & 1 & Neutral facial expression \\
& Grimace & 2 & Score only if definite negative facial expression
\end{tabular}


APPENDIX continued

\begin{tabular}{|c|c|c|c|}
\hline Item & Behaviour & Score & Definition \\
\hline \multirow[t]{5}{*}{ Child verbal } & None & 1 & Child not talking \\
\hline & Other complaints & 1 & $\begin{array}{l}\text { Child complains, but not about pain, e.g., } \\
\text { "I want to see mommy" or "I am thirsty" }\end{array}$ \\
\hline & Pain complaints & 2 & Child complains about pain \\
\hline & Both complaints & 2 & $\begin{array}{l}\text { Child complains about pain and about other things, } \\
\text { e.g., "It hurts; I want mommy" }\end{array}$ \\
\hline & Positive & 0 & $\begin{array}{l}\text { Child makes any positive statement or talks about } \\
\text { other things without complaint }\end{array}$ \\
\hline \multirow[t]{6}{*}{ Torso } & Neutral & 1 & Body (not limbs) is at rest; torso is inactive \\
\hline & Shifting & 2 & Body is in motion in a shifting or serpentine fashion \\
\hline & Tense & 2 & Body is arched or rigid \\
\hline & Shivering & 2 & Body is shuddering or shaking involuntarily \\
\hline & Upright & 2 & Child is in a vertical or upright position \\
\hline & Restrained & 2 & Body is restrained \\
\hline \multirow[t]{5}{*}{ Touch } & Not touching & 1 & Child is not touching or grabbing at wound \\
\hline & Reach & 2 & Child is reaching for but not touching wound \\
\hline & Touch & 2 & Child is gently touching wound or wound area \\
\hline & Grab & 2 & Child is grabbing vigorously at wound \\
\hline & Restrained & 2 & Child's arms are restrained \\
\hline \multirow[t]{5}{*}{ Legs } & Neutral & 1 & $\begin{array}{l}\text { Legs may be in any position but are relaxed; } \\
\text { includes gentle swimming or serpentine-like } \\
\text { movements }\end{array}$ \\
\hline & Squirming/kicking & 2 & $\begin{array}{l}\text { Definitive uneasy or restless movements in the } \\
\text { legs and/or striking out with foot or feet }\end{array}$ \\
\hline & Drawn up/Tensed & 2 & $\begin{array}{l}\text { Legs tensed and/or pulled up tightly to body and } \\
\text { kept there }\end{array}$ \\
\hline & Standing & 2 & Standing, crouching, or kneeling \\
\hline & Restrained & 2 & Child's legs are being held down \\
\hline
\end{tabular}

\section{Acknowledgements}

The authors would like to thank all members of the consultant and resident surgical and anaesthetic staff who participated enthusiastically in the tria.

The research assistant who carried out the observations and did the data input was employed by the University of the West Indies for the duration of the trial.

Ms. L. Grannum of the Medical Sciences Education Department produced the illustrations.

\section{References}

1 Lloyd-Thomas $A R$. Pain management in paediatric patients. Br J Anaesth 1990; 64: 85-104.

2 Lloyd-Thomas $A$. Assessment and control of pain in children (Editorial). Anaesthesia 1995; 50: 753-5.
3. Smerdlow $M$, Jones $R$. The duration of action of bupivacaine, prilocaine and lignocaine. Br J Anaesth 1970; 42: 335-9.

4 Shandling B, Steward DJ. Regional analgesia for postoperative pain in pediatric outpatient surgery. J Pediatr Surg 1980; 15: 477-80.

5 Cross GD, Barrett RF. Comparison of two regional techniques for postoperative analgesia in children following herniotomy and orchidopexy. Anaesthesia 1987; 42: 845-9.

6 McGrath PJ, Unruh AM. The measurement and assessment of pain. In: Pain Research and Clinical Management. Vol 1. Pain in Children and Adolescents. Oxford: Elsevier 1987: 91-2.

7 Dean $A G$, Dean JA, Burton AH, Dicker RC. Epi Info, Version 5. A word processing, database, and statistics 
program for epidemiology on microcomputers. Stone Mountain, Georgia: USD Inc, 1990.

8 Dixon WJ. BMDP Statistical Software Manual. California: University Press 1992: 598-601.

9 Lwanga SK, Lemeshow S. Sample size determination in health studies. A Practical Manual. World Health Organization, Geneva. 1991: 35.

10 Splinter WM, Bass J, Komocar L. Regional anaesthesia for hernia repair in children: local vs caudal anaesthesia. Can J Anaesth 1995; 42: 197-200.

11 Scott AD, Phillips A, White JB, Stow PJ. Analgesia following inguinal herniotomy or orchidopexy in children: a comparison of caudal and regional blockade. J R Coll Surg Edinb 1989; 34: 143-5.

12 Conroy JM, Othersen HB, Dorman BH, Gottesman JD, Wallace CT, Braben NH. A comparison of wound instillation and caudal block for analgesia following pediatric inguinal herniorrhaphy. J Pediatr Surg 1993; 28: 565-7.

13 Langer JC, Shandling B, Rosenberg $M$. Intraoperative bupivacaine during outpatient hernia repair in children: a randomized double blind trial. J Pediatr Surg 1987; 22: 267-70.

14 Harrison $C A$, Morris $S$, Harvey JS. Effect of ilioinguinal and ilio-hypogastric nerve block and wound infiltration with $0.5 \%$ bupivacaine on postoperative pain after hernia repair. Br J Anaesth 1994; 72: 691-3.

15 Ding $Y$, White PF. Post-herniorrhaphy pain in outpatients after pre-incision inguinal-hypogastric nerve block during monitored anaesthesia care. Can J Anaesth 1995; 42: 12-5.

16 Amid PK, Shulman AG, Lichtenstein IL. Local anesthesia for inguinal hernia repair step-by-step procedure. Ann Surg 1994; 220: 735-7.

17 Mc Cleane G, Mackle E, Stirling I. The addition of triamcinolone acetonide to bupivacaine has no effect on the quality of analgesia produced by ilioinguinal nerve block. Anaesthesia 1994; 49: 819-20.

18 Alexander JL, Hill RG. Basic mechanisms of pain and pain relief. In: Postoperative Pain Control. Oxford Blackwell Scientific Publications 1987: 28.

19 Anonymous. Postoperative pain relief and non-opioid analgesics (Editorial). Lancet 1991; 337: 524-6.

20 Gadiyar V, Gallagher TM, Crean PM, Taylor RH. The effect of a combination of rectal diclofenac and caudal bupivacaine on postoperative analgesia in children. Anaesthesia 1995; 50: 820-2.

21 Reid MF, Harris R, Pbillips PD, Barker I, Pereira NH, Bennett NR. Day-care herniotomy in children. A comparison of ilio-inguinal nerve block and wound infiltration for postoperative analgesia. Anaesthesia 1987; 42: 658-61. 